\title{
Management of paediatric asthma
}

\author{
Green RJ \\ Department of Paediatrics and Child Health, University of Pretoria \\ Corresponding author:Robin.green@up.ac.za
}

\section{Introduction}

Asthma, together with allergic rhinitis, are the commonest chronic conditions in children ${ }^{1}$ and despite our understanding of the pathophysiology, clinical presentation and having excellent asthma therapies, the disease remains poorly controlled. ${ }^{2}$

Asthma is diagnosed on the basis of recurrent 'troublesome lung symptoms,' (chronic cough and wheeze). ${ }^{3}$

Once the diagnosis of asthma is made in a child, and that includes children of all ages, intervention with an inhaled corticosteroid trial is perfectly acceptable. Children require special tools to be able to use inhalers and those include spacers and powder devices.

That is often the easy part of asthma management. What should happen next is where we are letting our patients and children down.

\section{Asthma control}

Asthma control means the extent to which the effects of asthma can be seen in the patient, or have been reduced or removed by treatment. ${ }^{4}$

Recent Global Initiative for Asthma (GINA) guidelines have suggested that monitoring of asthma control is essential in all asthmatics. ${ }^{4}$ (See Figure 1 for GINA assessment of asthma control.) Assessment of control should include symptoms (over the last week and month), and quality of life. In addition, the risk of future exacerbations (spirometry and possibly exhaled nitric oxide), and medication side-effects (oral symptoms and growth in children) must be regularly assessed. Formal tools for assessing control offer the best insight into asthma control. ${ }^{5}$ No test is a gold standard and all tests must be used in conjunction to assess control. ${ }^{6}$

- Exacerbations
Recommendation 1. Once an asthmatic is on controller therapy, regular assessment of control is critical. Of equal importance is regular assessment of future risk (exacerbations and side-effects).

Recommendation 2. Control must be formally measured at every visit, and every 3 months.

Recommendation 3. Formal tools for assessing control include symptom assessments, scores (such as the childhood Asthma Control Test (CACT $)^{7}$ and Asthma Control Questionnaire (ACQ)), and spirometry.

\section{Reasons for problematic asthma control}

- Incorrect diagnosis.

- Poorly educated patient - non-adherent to regular therapy, inability to use inhaler devices.

- Hidden allergens/sensitisers.

- Hidden triggers - especially environmental tobacco smoke (ETS).

- Co-morbidity - especially allergic rhinitis.

\section{GINA assessment of asthma control}

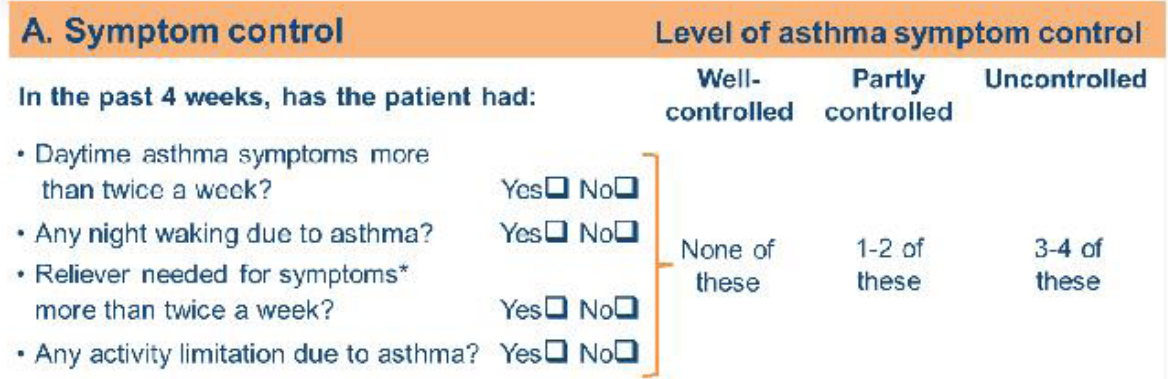

\section{B. Risk factors for poor asthma outcomes Future Risk}

- Assess risk factors at diagnosis and periodically

- Measure $\mathrm{FEV}_{1}$ at start of treatment, after 3-6 months of controller treatment to record the patient's personal best, then periodically for ongoing risk assessment

ASSESS PATIENT'S RISKS FOR:

- Fixed airflow limitation

- Medication side-effects

Figure 1. GINA assessment of asthma control and future risk ${ }^{4}$ 
Asthma control is significantly more likely in patients that are educated (know their disease), are regularly taught to use the inhaler device, have a written action plan and educational material (www.asthma.co.za) and are encouraged to use controller medication regularly. ${ }^{8}$

\section{Asthma education}

This is the most important aspect of your care of asthmatic children. It is unfortunately the most time-consuming part of your practice. Patient and caregiver education should be such that they take responsibility for a solution that actually works. The most important points in patient education are listed in Table I.

Table I. Components of patient education

Explain the inflammatory nature of the disease and need for regular
control (adherence).
Describe and regularly check delivery methods for medication,
especially inhalers (technique).
Use of therapies for co-morbid conditions (especially allergic rhinitis).
Treatment of flares and exacerbations.
Monitor control of the disease.
Regular check-ups.
Avoid known allergens (including hidden sources) and irritants.
Avoid unnecessary and unsafe therapies and practices.
Provide written material or reputable web addresses for such access.

Education is thus time-consuming but is THE unavoidable component that must be provided if you wish to successfully translate good therapy into successful therapy.

Some tools to aiding education include those listed in Table II.

Table II. Tools for patient education

Make your waiting rooms educationally rich (posters and other catchy displays).

Have a display where patients can freely pick up brochures of interest. Allow your patients to ask the questions that they may have.

Make sure staff are able to answer questions.

Have a range of demo devices.

Have a medication chart.

Provide directed literature after each consultation.

Provide reputable web addresses (on your educational material or prescription).

Provide control diaries.

Provide contact details for emergencies.

There is a potentially endless list of factors that may prevent patients from achieving control of their asthma. Table III lists but a few of these. Some are beyond your control but ensure that you do what you must to ensure control and thereby a normal life for your asthmatic patient.

Table III. Patient-related factors that may impact on achieving ideal control of asthma

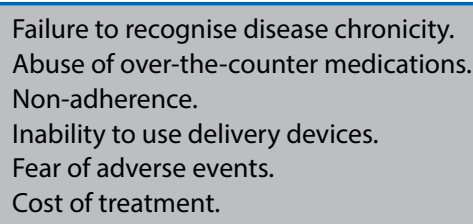

Knowledge of atopic conditions and their management does not guarantee success in therapy. Successful therapy, or a solution that works, requires more than a great medical mind. It requires all the subtleties of a successful educational message. Ensure your reputation is built on getting children to a normal life.

Recommendation 4. If control is sub-optimal check all reasons and educate the patient. A small number of patients need treatment adjustment.

\section{Adjusting therapy}

\section{Doubling ICS dose or adding a LABA at Step 3}

All asthmatic children with moderately severe asthma require a daily ICS (Step 2). Studies and a meta-analysis of paediatric studies (children aged 6-11 years old) for the addition of therapy in asthmatics not well controlled on low dose ICS (Steps 3 and 4), has revealed that adding a LABA improves lung function but does not reduce exacerbations more than double or higher ICS doses. ${ }^{9,10}$

Recommendation 5. For uncontrolled asthma in children older than five years using a low dose ICS, doubling the dose of ICS is preferred to adding a LABA.

LABA use should be considered where ICS local (oral thrush, dysphonia) or systemic side-effects (growth disturbance or disturbance of hypothalamo-pituitary axis function) occur or are suspected. It must be remembered that LABA use is not without side-effects and possible tolerance and/or tachyphylaxis.

Recommendation 6. Where ICS are causing local or systemic sideeffects, or there is a risk of such side-effects, LABA addition is preferred for poorly-controlled asthma.

Recommendation 7. What is critical in more severe asthma, before the dose of ICS is increased or a new drug is added, is to thoroughly assess the reasons for poor control, including reconsidering the diagnosis, education of patients (especially inhaler technique) and treatment of co-morbidities.

\section{Addition of a leukotriene receptor antagonist (LTRA) at Step 3}

One study explored tools to decide on the addition of an LTRA in children, including urinary leukotriene $E_{4}$ levels. Higher levels favoured LTRA over LABA step-up therapy. Predictors of differential responses comparing ICS with LTRA step-up therapy were not apparent, probably because of suppression of allergic markers with low-dose ICS treatment. ${ }^{11}$ Minimal overlap was seen across $\mathrm{FEV}_{1}$ and asthma control day predictors, suggesting distinct mechanisms related to lung function and asthma control day responses.

Two meta-analyses of LTRA as add-on therapy in children with more severe asthma were reported and demonstrated that the addition of anti-leukotrienes to ICS is not associated with a statistically significant reduction in the need for rescue oral corticosteroids or hospital admission, compared to the same or an increased dose of ICS in children and adolescents with mild to moderate asthma. ${ }^{10,12}$

Although anti-leukotrienes have been licensed for use in children for over 10 years, the paucity of paediatric trials, the absence 
of data on preschoolers, and the variability in the reporting of relevant clinical outcomes considerably limit firm conclusions. ${ }^{12}$

The LTRA option may be considered where steroid side-effects are suspected or confirmed or where there is parental concern for higher steroid doses +/- LABA use.

Recommendation 8. At present, there is no firm evidence to support the efficacy and safety of anti-leukotrienes as add-on therapy to ICS as a Step-3 option in the therapeutic arsenal for children with uncontrolled asthma symptoms on low-dose ICS. ${ }^{12}$ They might be considered as a third-line option instead of doubling the dose of ICS or adding a LABA.

Studies of LABA efficacy and safety are limited in preschool children. ${ }^{13}$

Recommendation 9. LABA use has not been well studied in preschool children and efficacy and safety have not been established. They should not be used in these children.

\section{References}

1. ISAAC Steering Committee. Worldwide variation in prevalence of symptoms of asthma, allergic rhinoconjunctivitis and atopic eczema. ISAAC. Lancet 1998; 351:1225-32.

2. Sullivan PW, Ghushchyan V, Kavati A, Navaratnam P, Friedman HS, Ortiz B. Trends in asthma control, treatment, health care utilization, and expenditures among children in the United States by place of residence: 2003-2014. J Allergy Clin Immunol Pract 2019 pii: S2213-2198(19)30164-3.

3. Bisgaard H, Pipper CB, Bønnelykke K. Endotyping early childhood asthma by quantitative symptom assessment. J Allergy Clin Immunol 2011;127(5):11551164.e2.

4. www.ginasthma.org 2016. [Accessed 20 March 2019].

5. Deschildre A, Pin I, El Abd K, et al. Asthma control assessment in a pediatric population: comparison between GINA/NAEPP guidelines, Childhood Asthma Control Test (C-ACT), and physician's rating. Allergy 2014;69(6):784-90.

6. Green RJ, Klein M, Becker $P$, et al. Disagreement between common measures of asthma control. CHEST 2013;143:117-122.

7. http://www.ccwjc.com/Forms/Asthma/Tools/Childhood\%20Asthma\%20 Control\%20Test\%20Ages\%204-11\%20-\%20English.pdf. [Accessed 22 March 2019].

8. Schuers M, Chapron A, Guihard H, Bouchez T, Darmon D. Impact of non-drug therapies on asthma control: A systematic review of the literature. Eur J Gen Pract 2019;8:1-12.

9. Israel E, Roche N, Martin RJ, et al. Increased dose of inhaled corticosteroid versus add-on long-acting $\beta$-agonist for step-up therapy in asthma. Ann Am Thorac Soc 2015;12(6):798-806.

10. Castro-Rodriguez JA, Rodrigo GJ, Rodriguez-Martinez CE. Principal findings of systematic reviews for chronic treatment in childhood asthma. J Asthma 2015;52(4):407-16.

11. Rabinovitch N, Mauger DT, Reisdorph N, et al. Predictors of asthma control and lung function responsiveness to step 3 therapy in children with uncontrolled asthma. J Allergy Clin Immunol 2014;133(2):350-6.

12. Chauhan BF, Ben Salah R, Ducharme FM. Addition of anti-leukotriene agents to inhaled corticosteroids in children with persistent asthma. Cochrane Database Syst Rev 2013;10:CD009585.

13. Data on file. GSK 2003 
Appendix A. Childhood Asthma Control Test

Name

Date

Childhood Asthma Control Test for Children 4 to 11 years

This test will provide a score that might help a doctor determine if your child's axthma treatment plan is working or if it might be time for a change.

Step 1. Child answers. Let your child answer the first four questions ( 1 to 4$)$. If your child needs belp reading or understanding the question, you may help, but let your child select the response. There are no right or wrong answers.

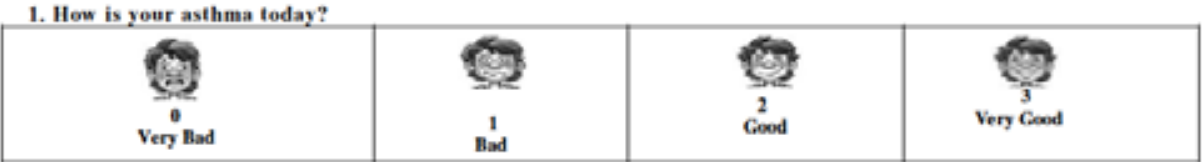

2. How much of a proble $m$ is your asthma when your run, exereise or play sperts?

\begin{tabular}{|c|c|c|c|}
\hline $\begin{array}{l}\text { I's a big problerm; I can'l do what I } \\
\text { want to do }\end{array}$ & $\begin{array}{l}1 \\
\text { It's a problem asd I } \\
\text { doa'it like it }\end{array}$ & $\begin{array}{l}\text { It's a linte problem but } \\
\text { its skay }\end{array}$ & $\stackrel{3}{3}$ Irs not a problem \\
\hline
\end{tabular}

3. Do you cough because of your asthma?

\begin{tabular}{|c|c|c|c|}
\hline Yes, all of the time & $\begin{array}{c}1 \\
\text { Yes, most of the tims. }\end{array}$ & Yes, some of the time & No, noox of the tims. \\
\hline
\end{tabular}

4. Do you wake up during the night because of your asthma?

\begin{tabular}{|c|c|c|c|}
\hline & & \\
\hline
\end{tabular}

Step 2. Parents answer. Parents, complete the remaining question (5 to 7) on your own without letting your child's responses influence your answers.

5. During the last 4 weeks, how many days did your child have any daytime asthma symptoms? (ex cough, chest tightness)

\begin{tabular}{|c|c|c|c|c|c|}
\hline $\begin{array}{c}5 \\
\text { Not at all }\end{array}$ & $\stackrel{4}{1-3}$ days $^{4}$ & $\stackrel{3}{4}_{4}$ days & $\stackrel{2}{11-18 \text { days }}$ & $\begin{array}{c}1 \\
19.24 \text { days }\end{array}$ & $\begin{array}{c}0 \\
\text { Everyday }\end{array}$ \\
\hline
\end{tabular}

6. During the last 4 weeks, how many days did your child wheeze during the day because of asthma?

\begin{tabular}{|cccccc|}
\hline 5 & 4 & 3 & 2 & 1 & 0 \\
Not at all & $1-3$ days & $4-10^{\text {days }}$ & $11-18$ days & 19.24 days & Everyday \\
\hline
\end{tabular}

7. During the last 4 weeks, how many days did your child wake up during the night because of asthma?

\begin{tabular}{|cccccc|}
\hline 5 & 4 & 3 & 2 & 1 & 0 \\
Not at all & $1-3$ days & $4-10$ days & $11-18$ days & $19-24$ days & Everyday \\
\hline
\end{tabular}

Step 3. Write the number of each answer in the score box to the right

Step 4. Add up each score box for the total score.

be a sign that your child's asthma is not

controled as well as it could be. Talk to

your child's doctor about the results.

Siep 5. Talk to you doctor about your child's total score.

nen-1

